\title{
Erratum: Collisions of room-temperature helium with ultracold lithium and the van der Waals bound state of HeLi [Phys. Rev. A 101, 012702 (2020)]
}

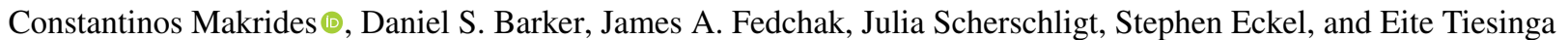

(Received 20 January 2022; published 28 February 2022)

DOI: 10.1103/PhysRevA.105.029902

We have found an error in the computation of the thermally averaged total elastic rate coefficient for the collision of a room-temperature helium atom with an ultracold lithium atom presented. We omitted the factor of $2 / \sqrt{\pi}$ in the normalization over the Boltzmann distribution. Our corrected prediction for the thermally averaged rate coefficient for a $300-\mathrm{K}$ helium gas and a $1-\mu \mathrm{K} \mathrm{Li}$ gas is $1.655(15) \times 10^{-9} \mathrm{~cm}^{3} / \mathrm{s}$ for ${ }^{4} \mathrm{He}+{ }^{6} \mathrm{Li}$ and $1.659(15) \times 10^{-9} \mathrm{~cm}^{3} / \mathrm{s}$ for ${ }^{4} \mathrm{He}+{ }^{7} \mathrm{Li}$ where the numbers in parentheses are the one-standard-deviation uncertainties in the last two significant digits. The temperature dependence of the rate coefficients must be corrected with the same factor.

The corrected total elastic rate coefficient $K\left(T_{\mathrm{He}}, T_{\mathrm{Li}}\right)$ for the ${ }^{4} \mathrm{He}+{ }^{7} \mathrm{Li}$ collision are shown in Fig. 1 as functions of ${ }^{4} \mathrm{He}$ temperature $T_{\mathrm{He}}$ with lithium temperature $T_{\mathrm{Li}}=1 \mu \mathrm{K}$. Results are presented for four Born-Oppenheimer electronic potentials, defined in the original paper and representing electronic structure calculations of different complexity and accuracy.

Near room temperature, the thermalized rate constants are functionally close to linear and well represented by

$$
K\left(T_{\mathrm{He}}, T_{\mathrm{Li}}\right)=\mathcal{K}_{0}+\mathcal{K}_{1}\left(T_{\mathrm{He}}-T_{\mathrm{RT}}\right)+\frac{1}{2} \mathcal{K}_{2}\left(T_{\mathrm{He}}-T_{\mathrm{RT}}\right)^{2}+\frac{m_{\mathrm{He}}}{m_{\mathrm{Li}}} \mathcal{K}_{1}\left(T_{\mathrm{Li}}-1 \mu \mathrm{K}\right),
$$

with coefficients $\mathcal{K}_{i}$ and $T_{\mathrm{RT}}=300 \mathrm{~K}$. The corrected values and one-standard-deviation uncertainties for the coefficients can be found in Table I for both ${ }^{4} \mathrm{He}+{ }^{6} \mathrm{Li}$ and ${ }^{4} \mathrm{He}+{ }^{7} \mathrm{Li}$. For an explanation of the uncertainties, see the original paper.

We acknowledge help from Dr. J. Kłos in resolving this error.

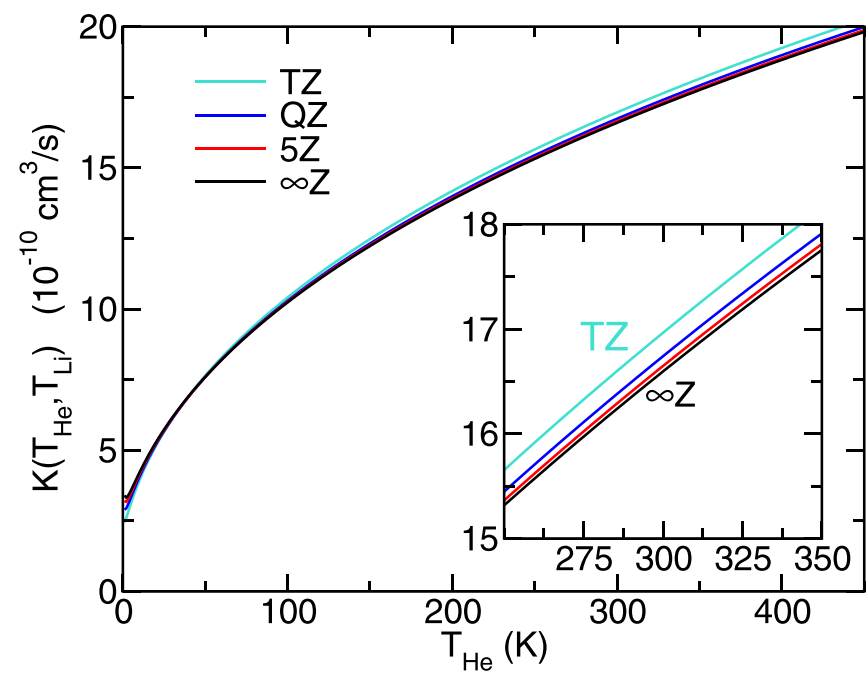

FIG. 1. Thermalized rate coefficients $K^{x Z}\left(T_{\mathrm{He}}, T_{\mathrm{Li}}\right)$ as functions of the ${ }^{4} \mathrm{He}$ temperature $T_{\mathrm{He}}$ with ${ }^{7} \mathrm{Li}$ held at $T_{\mathrm{Li}}=1 \mu \mathrm{K}$. The nearly overlapping turquoise, blue, red, and black solid lines are $K^{x Z}$ for $x=T, Q, 5$, and $\infty$, respectively. Here, $x$ labels Born-Oppenheimer potentials. The inset shows a blowup of the region $250 \mathrm{~K} \leqslant T_{\mathrm{He}} \leqslant 350 \mathrm{~K}$ where the differences in $K^{x Z}$ can be better seen. 
TABLE I. Predicted values and one-standard-deviation uncertainties for expansion coefficients $\mathcal{K}_{0}, \mathcal{K}_{1}$, and $\mathcal{K}_{2}$ of the thermalized total rate coefficient $K\left(T_{\mathrm{He}}, T_{\mathrm{Li}}\right)$ as defined in Eq. (1) for near room-temperature helium and $1-\mu \mathrm{K}{ }^{6,7} \mathrm{Li}$ sensor atoms with $T_{\mathrm{RT}}=300 \mathrm{~K}$. The uncertainty $\sigma(K)$ is found by error propagation with correlation coefficients $r\left(\mathcal{K}_{i}, \mathcal{K}_{j}\right)=1$ when $i \neq j$.

\begin{tabular}{lccr}
\hline \hline & $\begin{array}{c}\mathcal{K}_{0} \\
\left(\mathrm{~cm}^{3} / \mathrm{s}\right)\end{array}$ & $\begin{array}{c}\mathcal{K}_{1} \\
\left(\mathrm{~cm}^{3} / \mathrm{s} / \mathrm{K}\right)\end{array}$ & $\begin{array}{c}\mathcal{K}_{2} \\
\left(\mathrm{~cm}^{3} / \mathrm{s} / \mathrm{K}^{2}\right)\end{array}$ \\
\hline${ }^{4} \mathrm{He}{ }^{6} \mathrm{Li}$ & $1.655(15) \times 10^{-9}$ & $2.432(27) \times 10^{-12}$ & $-4.672(81) \times 10^{-15}$ \\
${ }^{4} \mathrm{He}{ }^{7} \mathrm{Li}$ & $1.659(15) \times 10^{-9}$ & $2.429(27) \times 10^{-12}$ & $-4.661(85) \times 10^{-15}$ \\
\hline \hline
\end{tabular}

